\title{
Mitochondrial Uncoupling Proteins (UCP1-UCP3) and Adenine Nucleotide Translocase (ANT1) Enhance the Protonophoric Action of 2,4-Dinitrophenol in Mitochondria and Planar Bilayer Membranes
}

\author{
Kristina Žuna ${ }^{1}\left(\mathbb{D}\right.$, Olga Jovanović ${ }^{1}$, Ljudmila S. Khailova ${ }^{2}$, Sanja Škulj ${ }^{3} \mathbb{D}$, Zlatko Brkljača ${ }^{4}$, Jürgen Kreiter ${ }^{1}$, \\ Elena A. Kotova ${ }^{2}$, Mario Vazdar 4,5 (D), Yuri N. Antonenko ${ }^{2, *(D)}$ and Elena E. Pohl 1,*(D) \\ 1 Institute of Physiology, Pathophysiology and Biophysics, University of Veterinary Medicine, \\ A-1210 Vienna, Austria; kristina.zuna@vetmeduni.ac.at (K.Ž.); olga.jovanovic@vetmeduni.ac.at (O.J.); \\ jürgen.kreiter@vetmeduni.ac.at (J.K.) \\ 2 Belozersky Institute of Physico-Chemical Biology, Lomonosov Moscow State University, Leninskie Gory 1/40, \\ 119991 Moscow, Russia; khailova@genebee.msu.ru (L.S.K.); kotova@belozersky.msu.ru (E.A.K.) \\ 3 Department of Chemistry, Faculty of Science, University of Zagreb, Horvatovac 102a, 10000 Zagreb, Croatia; \\ Sanja.Skulj@irb.hr \\ 4 Division of Organic Chemistry and Biochemistry, Ruđer Bošković Institute, Bijenička 54, \\ 10000 Zagreb, Croatia; Zlatko.Brkljaca@irb.hr (Z.B.); Mario.Vazdar@irb.hr (M.V.) \\ check for \\ updates \\ Citation: Žuna, K.; Jovanović, O.; \\ 5 Institute of Organic Chemistry and Biochemistry, Czech Academy of Sciences, Flemingovo nám. 2, \\ 16610 Prague, Czech Republic \\ * Correspondence: antonen@belozersky.msu.ru (Y.N.A.); elena.pohl@vetmeduni.ac.at (E.E.P.)
} Khailova, L.S.; Škulj, S.; Brkljača, Z.; Kreiter, J.; Kotova, E.A.; Vazdar, M.; Antonenko, Y.N.; Pohl, E.E. Mitochondrial Uncoupling Proteins (UCP1-UCP3) and Adenine

Nucleotide Translocase (ANT1) Enhance the Protonophoric Action of 2,4-Dinitrophenol in Mitochondria and Planar Bilayer Membranes. Biomolecules 2021, 11, 1178. https:// doi.org/10.3390/biom11081178

Academic Editor: Brigita Urbanc

Received: 21 June 2021

Accepted: 4 August 2021

Published: 9 August 2021

Publisher's Note: MDPI stays neutral with regard to jurisdictional claims in published maps and institutional affiliations.

Copyright: () 2021 by the authors. Licensee MDPI, Basel, Switzerland. This article is an open access article distributed under the terms and conditions of the Creative Commons Attribution (CC BY) license (https:// creativecommons.org/licenses/by/ $4.0 /)$.

\begin{abstract}
Dinitrophenol (DNP) is a classic uncoupler of oxidative phosphorylation in mitochondria which is still used in "diet pills", despite its high toxicity and lack of antidotes. DNP increases the proton current through pure lipid membranes, similar to other chemical uncouplers. However, the molecular mechanism of its action in the mitochondria is far from being understood. The sensitivity of DNP's uncoupling action in mitochondria to carboxyatractyloside, a specific inhibitor of adenine nucleotide translocase (ANT), suggests the involvement of ANT and probably other mitochondrial proton-transporting proteins in the DNP's protonophoric activity. To test this hypothesis, we investigated the contribution of recombinant ANT1 and the uncoupling proteins UCP1-UCP3 to DNP-mediated proton leakage using the well-defined model of planar bilayer lipid membranes. All four proteins significantly enhanced the protonophoric effect of DNP. Notably, only long-chain free fatty acids were previously shown to be co-factors of UCPs and ANT1. Using site-directed mutagenesis and molecular dynamics simulations, we showed that arginine 79 of ANT1 is crucial for the DNP-mediated increase of membrane conductance, implying that this amino acid participates in DNP binding to ANT1.
\end{abstract}

Keywords: mitochondrial uncoupler; protonophore; membrane potential; proton conductance; artificial membranes; molecular dynamics simulations

\section{Introduction}

Obesity is one of the most acute health problems in developed countries worldwide. Recent statistics from the World Health Organization show that obesity has nearly tripled worldwide since 1975 (https: / / www.who.int/news-room/ fact-sheets/detail/obesity-andoverweight, accessed on 5 June 2021). Although the uncoupling of oxidative phosphorylation (OxPhos) in the mitochondria was long ago proposed as a target for treating obesity, no breakthrough therapy has yet been established. 2,4-Dinitrophenol (DNP) has been known since the mid-1930s as an effective component of "diet pills" that is capable of reducing obesity by increasing the basal metabolic rate [1]. Severe side effects forced its withdrawal from the pharmaceutical market $[2,3]$. However, DNP can still be illegally purchased under 
different names over the internet as a drug conferring rapid and supposedly safe weight loss, and is also used as an illegal food supplement [4].

Sustained scientific interest in DNP is based not only on its much higher efficacy than other drugs but also on the need to develop antidotes against its toxicity to prevent the increasing number of deaths associated with its uncontrolled use. The detailed molecular mechanism of the uncouplers' action in the mitochondria remains unclear, which hinders the use of DNP and its derivatives as therapeutic drugs.

Since DNP increases the conductance of pure lipid membranes, similar to other uncouplers [5-14], its effect on the mitochondria was ascribed to an increase in proton permeability through the lipid part of the inner mitochondrial membrane (IMM). On the other hand, the azido-substituted analog of DNP, 2-azido-4-nitrophenol, was shown to bind effectively to mitochondrial proteins [15-17]. In addition, the uncoupling effect of DNP on the mitochondria was shown to be partially blocked by carboxyatractyloside (CATR) $[18,19]$, a specific inhibitor of the adenine nucleotide translocase (ANT), indicating the participation of ANT in the uncoupling action of DNP in the mitochondria.

Partial suppression of the uncoupling effect was also found for other protonophores, including BAM15 [19-24]. These findings support the hypothesis of ANT's participation in the uncoupling action of certain protonophores in the mitochondria [25].

Our previous study demonstrated the ability of ANT1 to enhance the proton current across artificial membranes in the presence of weak uncouplers-long-chain fatty acids (FA) [26]. We now hypothesize that DNP's protonophoric function may be also potentiated by mitochondrial proton-transporting proteins, in addition to the DNP-mediated increase in the selective lipid membrane's permeability for protons. To test this hypothesis, we used a well-defined model of lipid bilayer membranes reconstituted with recombinant ANT1 or UCPs (1) to investigate the contribution of these proteins to DNP-mediated proton leakage, (2) to evaluate the efficiency of the inhibitors of proton transport mediated by ANT1/UCP, and (3) to reveal the amino acids crucial for ANT1 activation by DNP.

\section{Materials and Methods}

\subsection{Chemicals}

2,4-Dinitrophenol (DNP), chloroform, dimethyl sulfoxide (DMSO), 1,2-dioleoyl-snglycero-3-phosphotidylcholine (DOPC), 1,2-dioleoyl-sn-glycero-3-phosphoethanolamine (DOPE), cardiolipin (CL), sodium sulfate $\left(\mathrm{Na}_{2} \mathrm{SO}_{4}\right), 2-(N$-morpholino) ethanesulfonic acid (MES), tris(hydroxymethyl)-aminomethane (Tris), adenosine $5^{\prime}$-triphosphate (ATP), guanosine $5^{\prime}$-triphosphate (GTP), carboxyatractyloside (CATR), ethylenediaminetetraacetic acid (EDTA), ethylene glycol-bis( $\beta$-aminoethyl ether)- $\mathrm{N}, \mathrm{N}, \mathrm{N}^{\prime}, \mathrm{N}^{\prime}$-tetraacetic acid (EGTA), $N$ lauroylsarcosine, Triton X-114, dithiothreitol (DTT), bovine serum albumin (BSA), sucrose, 3-(N-morpholino) propanesulfonic acid (MOPS), rotenone, and safranin $\mathrm{O}$ were purchased from Sigma-Aldrich (Vienna, Austria). Arachidonic acid (AA) was purchased from Larodan (Solna, Sweden), n-octylpolyoxyethylene was purchased from BACHEM (Bubendorf, Switzerland), and hydroxyapatite was purchased from Bio-Rad Laboratories (Hercules, CA, USA).

\subsection{Cloning, Purification, and Reconstitution of Murine ANT1 and UCPS}

Cloning, purification, and reconstitution of murine ANT1, UCP1, UCP2, and UCP3 followed previously established protocols [27-29]. In brief, expression plasmids containing selected cDNA sequences were transformed into the E. coli Rosetta DE3 strain (Novagen (Merck), Darmstadt, Germany). After induction, high-pressure homogenization, and centrifugation, the proteins were isolated as inclusion bodies. For protein refolding, purification, and reconstitution, $1 \mathrm{mg}$ of the inclusion bodies was solubilized in a TE/G buffer containing $2 \% \mathrm{~N}$-lauroylsarcosine, $1.3 \%$ Triton $\mathrm{X}-114,0.3 \%$ n-octylpolyoxyethylene, $1 \mathrm{mM}$ DTT, and GTP at $\mathrm{pH}$ 7.5. Fifty milligrams of the lipid mixture (DOPC:DOPE:CL; 45:45:10 $\mathrm{mol} \%$ ) was mixed in gradually. The mixture was concentrated and dialyzed against a buffer used in the experiments $\left(50 \mathrm{mM} \mathrm{Na}_{2} \mathrm{SO}_{4}, 10 \mathrm{mM}\right.$ MES, $10 \mathrm{mM}$ Tris, and 
$0.6 \mathrm{mM}$ EGTA at $\mathrm{pH}$ 7.34). Unfolded and aggregated proteins were removed from the dialysate by centrifugation and through a column containing hydroxyapatite; non-ionic detergents were removed by applying Bio-Beads SM-2 (Bio-Rad Laboratories, Hercules, CA, USA). The protein concentration in proteoliposomes was measured with the Micro BCA Protein Assay Kit (Thermo Fisher Scientific, Waltham, MA, USA). Protein purity was verified by SDS-PAGE and silver staining (Figure S1). Proteoliposomes were produced in independent batches. The following batch numbers were used for this study: ANT1 \#42 and \#47, UCP1 \#117, UCP2 \#39, UCP3 \#31, and ANT1 R79S \#3.

\subsection{Generation of the ANT1 R79S Mutant}

In vitro site-directed mutagenesis was carried out on expression plasmids containing the cDNA of mANT1 as a template. The mutation was introduced with an oligonucleotide designed to alter codon Arg79 (CGG) to Ser (TCG) using a QuikChange II site-directed mutagenesis kit (Agilent Technologies, Vienna, Austria). The successful introduction of mutations was confirmed by sequencing. Mutant ANT1 expression plasmids were transformed in the E. coli expression strain Rosetta DE3. Expression induction, inclusion body isolation, and reconstitution into liposomes of the ANT1 mutant were performed as described above for the ANT1 wild-type.

\subsection{Formation of Planar Lipid Bilayer Membranes and Membrane Conductance Measurements}

Planar lipid bilayers were formed from proteoliposomes as described previously [30,31]. Correct membrane formation was verified by measuring the membrane capacitance $\left(C=0.72 \pm 0.02 \mu \mathrm{F} / \mathrm{cm}^{2}\right)$, which was independent of the presence of protein, AA and DNP. Current voltage measurements were performed with a patch-clamp amplifier (EPC 10, HEKA Elektronik, Dr. Schulze GmbH, Lambrecht, Germany). The specific total membrane conductance $\left(G_{\mathrm{m}}\right)$ at $0 \mathrm{mV}$ was obtained as the slope of a linear fit of the experimental data at the applied voltages from $-50 \mathrm{mV}$ to $+50 \mathrm{mV}$, normalized to the membrane area. AA solved in chloroform was added to the membrane-forming lipid solution. ATP dissolved in the assay buffer ( $\mathrm{pH}=7.34$ ), CATR, and DNP (both dissolved in DMSO) were added to the buffer solution before forming bilayer membranes. Control experiments showed that DMSO did not change the total membrane conductance of the lipid bilayers in the range of concentrations used [32]. The concentrations of each substrate are indicated in the figure legends. The relative conductance was calculated according to Equation (1):

$$
G_{r e l}=\frac{G-G_{0}}{G_{1}-G_{0}}
$$

where $G_{0}$ is the total membrane conductance of lipid membranes reconstituted with DNP, $G_{1}$ is the total membrane conductance of lipid membranes reconstituted with ANT1 and $\mathrm{DNP}$, and $G$ is the total specific membrane conductance of lipid membranes reconstituted with ANT1, DNP, and/or CATR/ATP (Figure 3).

\subsection{Isolation of Rat Liver Mitochondria}

Rat liver or heart mitochondria (RLM, RHM) were isolated by differential centrifugation [33] in a medium containing $250 \mathrm{mM}$ sucrose, $5 \mathrm{mM}$ MOPS, $1 \mathrm{mM}$ EGTA, and bovine serum albumin $(0.5 \mathrm{mg} / \mathrm{mL})$ at $\mathrm{pH}$ 7.4. The final washing was performed in a medium with the same composition. Protein concentration was determined using the Biuret method. Handling of animals and experimental procedures were conducted in accordance with international guidelines for animal care and use and were approved by the Ethics Committee of the Belozersky Institute of Physico-Chemical Biology at Moscow State University (protocol \#3 from 12 February 2018).

\subsection{Membrane Potential $(\Delta \psi)$ Measurements in Isolated Mitochondria}

The transmembrane electric potential difference $(\Delta \psi)$ was measured using safranin O dye [34]. An incubation medium containing $250 \mathrm{mM}$ sucrose, $5 \mathrm{mM}$ MOPS, $1 \mathrm{mM}$ 
EGTA, $2 \mu \mathrm{M}$ rotenone, $5 \mathrm{mM}$ succinate ( $\mathrm{pH}$ 7.4), and $15 \mu \mathrm{M}$ safranin $\mathrm{O}$ was used. The mitochondrial protein content measured by the Biuret method was $0.6 \mathrm{mg}$ protein $/ \mathrm{mL}$. The experiments were carried out at $26^{\circ} \mathrm{C}$.

The difference in absorbance between 555 and $523 \mathrm{~nm}(\triangle A)$ was recorded with an Aminco DW-2000 spectrophotometer (Olis Inc., Bogart, GA, USA) in dual wavelength mode.

Mitochondrial membrane potential (MMP) was normalized according to Equation (2):

$$
\text { Absorbance, } \% \text { of the maximum }=\frac{\Delta A_{\max }-\Delta A}{\Delta A_{\max }-\Delta A_{\min }} \times 100
$$

where $\Delta A$ is the difference between $A_{523}$ and $A_{555}, \Delta A_{\text {max }}$ is the highest membrane potential measured without the presence of DNP, and $\Delta A_{\min }$ is the lowest MMP measured in the presence of DNP at the highest concentration. Statistical analysis was performed using a Student's test with a level of significance of 0.01 .

\subsection{Molecular Dynamic Simulations}

We performed all-atom molecular dynamic (MD) simulations of wild-type and mutated (R79 to S79) ANT1 protein in a 1,2-dioleoyl-sn-glycero-3-phosphocholine (DOPC) bilayer. The initial structure for both the wild-type and mutated forms of ANT1 was taken from the end of the $2 \mu$ s simulation of the wild-type ANT1 protein in the DOPC bilayer [35], with the mutation of R79 into S79 and the subsequent introduction of the mutated form of ANT1 into the DOPC bilayer being performed using CHARMM-GUI (http:/ / www.charmm-gui.org/, accessed on 10 February 2021) [36-38]. Overall, 4 system set-ups were prepared: the wild-type ANT1 with the anionic form of 2,4-dinitrophenol (DNP) (i) or ATP ${ }^{4-}$ bound in the cytosolic-open state (ii), as well as the mutated ANT1 with the DNP anion (iii) or $\mathrm{ATP}^{4-}$ bound in the same position (iv). Since DNP has a $\mathrm{pKa}$ value in water of 4.1, we assumed it was anionic at the neutral pH used in MD simulations. All simulation boxes contained ANT1 protein (wild-type or the R79-to-S79 mutant) (with a total charge of $+19 \mathrm{e}$ or $+18 \mathrm{e}$, respectively), 73 DOPC molecules per leaflet (146 per system), 11,500 water molecules, a single DNP anion or $\mathrm{ATP}^{4-}$, and the necessary number of $\mathrm{Cl}^{-}$anions to neutralize the net charge, depending on whether wild-type ANT1 or its mutant was present in the system. ANT1 protein, $\mathrm{ATP}^{4-}$ ion, and DOPC lipids were described by the CHARMM36m force field [39]. The force field for the anionic form of the DNP (2,4-dinitrophenol) anion was built on the basis of the CHARMM general force field (CGenFF) [40] (https: / / cgenff.umaryland.edu/, accessed on 10 February 2021).

The system containing mutated ANT1 protein, DOPC molecules, and water/ions (no DNP anion or $\mathrm{ATP}^{4-}$ present at this stage) was first minimized and equilibrated in 6 steps using the CHARMM-GUI protocol [41] and then simulated for a further 500 ns without any restraints with a $2 \mathrm{fs}$ time step in a periodic rectangular box of $7.9 \mathrm{~nm} \times 7.9 \mathrm{~nm} \times$ $9.4 \mathrm{~nm}$ using the isobaric-isothermal ensemble (NPT) and periodic boundary conditions in all directions at $\mathrm{T}=310 \mathrm{~K}$, maintained via a Nosé-Hoover thermostat [42] independently for the DOPC, water/ions, and protein subsystems, with a coupling constant of $1.0 \mathrm{ps}^{-1}$. The pressure was set to 1.013 bar and controlled with a semi-isotropic Parrinello-Rahman barostat [43], with a time constant for pressure coupling of $5 \mathrm{ps}^{-1}$. Long-range electrostatics were calculated using the particle-mesh Ewald (PME) method [44] with real-space Coulomb interactions cut off at $1.2 \mathrm{~nm}$ using a Fourier spacing of $0.12 \mathrm{~nm}$ and a Verlet cut-off scheme.

To prepare the investigated systems, one molecule of DNP anion (or ATP ${ }^{-}$) was placed in the cytosolic-open state of the equilibrated systems containing wild-type ANT1 (obtained after $2 \mu$ s of free MD simulation) or mutated ANT1 (see previous paragraph). More precisely, the DNP anion (or $\mathrm{ATP}^{4-}$ ) was placed in the cavity of the ANT1 protein, in proximity to the R79 (wild-type) or S79 (mutated ANT1) amino acid residue, using the VMD molecular graphics program [45]. The prepared systems were then minimized, and short preliminary simulations ( $2 \mathrm{~ns}$ ) with positional restraints on the DNP (or ATP) molecule $\left(500 \mathrm{~kJ} \mathrm{~mol}^{-1} \mathrm{~nm}^{-2}\right.$ ) were conducted to relax the protein around the DNP 
molecule. Subsequently, both investigated systems were propagated for a duration of $500 \mathrm{~ns}$, with MD parameters equal to those used to propagate the mutated ANT1 system (see previous paragraph). All simulations were run with the GROMACS 2018 software package [46].

\subsection{Statistics}

Data analysis and fitting of electrophysiological measurements were performed using Sigma Plot 12.5 (Systat Software GmbH, Erkrath, Germany) and are displayed as the mean \pm SD of at least 3 independent experiments. Each independent experiment involved at least 3 measurements using independently formed bilayer membranes.

\section{Results}

\subsection{CATR Recouples Mitochondria Uncoupled by DNP}

Measurements of oxygen consumption in isolated rat liver mitochondria (RLM) and skeletal muscle mitochondria showed that CATR can partially reverse the uncoupling effect of low DNP concentrations [18,47]. Because mitochondrial membrane potential (MMP) is a more sensitive indicator of mitochondrial coupling, we measured the MMP of isolated RLM in the presence of DNP and CATR using the potential-sensitive dye safranin O [34]. Figure 1A shows that, after the addition of 10-50 $\mu \mathrm{M}$ DNP to RLM, MMP decreased in a concentration-dependent manner. CATR at a concentration of $3 \mu \mathrm{M}$ partially restored MMP at all concentrations, supporting the data obtained from oxygen consumption measurements earlier.

A

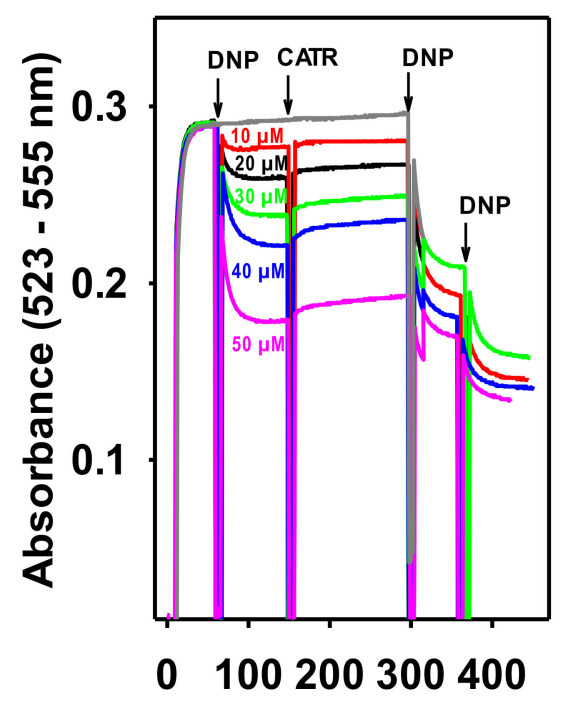

Time, $\mathbf{s}$
B

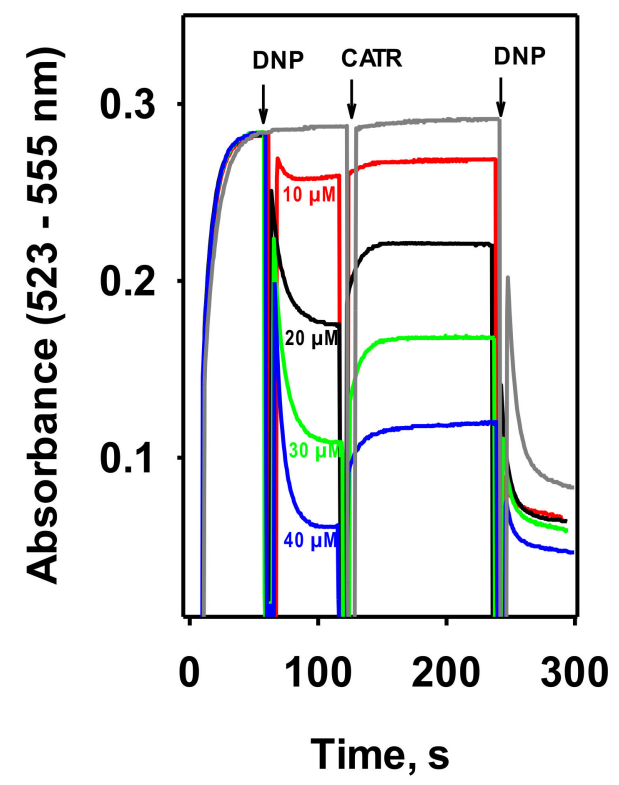

C

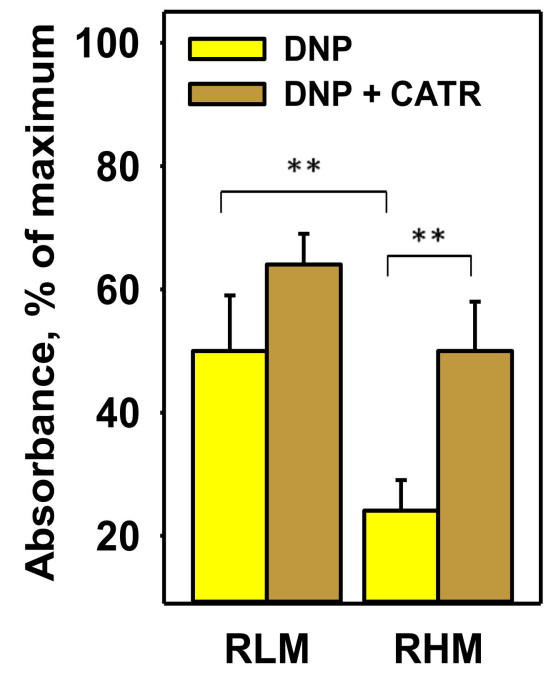

Figure 1. CATR recovers the DNP-mediated decrease in mitochondrial membrane potential (MMP) in isolated rat mitochondria. Representative recordings of MMP in rat liver mitochondria (A) and heart (B) mitochondria correspond to changes in the absorbance of the potential-sensitive dye safranin $\mathrm{O}(15 \mu \mathrm{M})$. CATR was added at a final concentration of $3 \mu \mathrm{M}$; the concentration of DNP (unless otherwise indicated) was $50 \mu \mathrm{M}$. The gray line represents the control measurement without the addition of CATR or DNP. (C) Quantification of MMP recovery by CATR (brown) in the presence of $30 \mu \mathrm{M}$ DNP (yellow, brown). Data are the mean \pm SD of at least three independent experiments; ${ }^{* *} p<0.01$. For other conditions, see Section 2 (Materials and Methods).

Because the DNP effect was small in RLM, we performed similar experiments with mitochondria isolated from rat hearts (RHM), which are known to have a higher ANT1 abundance [48]. The heart is also known to express another proton-transporting protein, 
UCP3 [49,50]. Figure 1B shows that the uncoupling effect of DNP in RHM was significantly higher than that in RLM. Importantly, the subsequent recoupling effect of CATR was also much more pronounced in RHM. A significant difference $(p<0.01)$ was found between RLM and RHM for both DNP-mediated uncoupling and recoupling in the presence of CATR (Figure 1C). Nonetheless, no complete recoupling was observed, suggesting a significant contribution of the DNP-assisted proton shuttling through the lipid part of membranes to the overall DNP-mediated proton transport and/or the involvement of other carrier proteins of IMM in this process.

\subsection{DNP Increases the Proton Conductance of the Membranes Reconstituted with Mitochondrial Membrane Proteins}

It was previously shown that ANT1 mediates proton transport in the presence of free long-chain fatty acids (FA), similar to UCPs $[26,47,51]$. To test whether DNP also activates ANT1, we used a well-defined model of planar bilayer membranes reconstituted with recombinant murine ANT1 (Figure S1) [27]. In contrast to the well-known Müller-Rudin technique, in which the membrane is "painted" by lipids dissolved in n-decane, we folded bilayers from the solvent-free monolayer formed from the proteoliposomes. The specific conductance $\left(\mathrm{G}_{\mathrm{m}}\right)$ of the membranes reconstituted with ANT1 $\left(\mathrm{G}_{\mathrm{m}}=11.1 \pm 0.8 \mathrm{nS} / \mathrm{cm}^{2}\right)$ was comparable with the conductance of pure lipid membranes made from DOPC, DOPE, and cardiolipin (CL) (45:45:10 $\mathrm{mol} \% ; \mathrm{G}_{\mathrm{m}}=10.81 \pm 2.72 \mathrm{nS} / \mathrm{cm}^{2}$, Figure $\left.2 \mathrm{~A}\right)$.

A

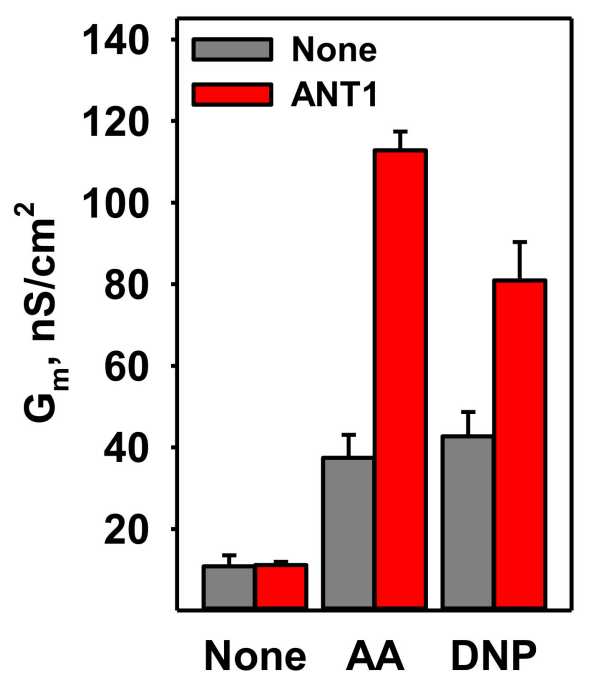

B

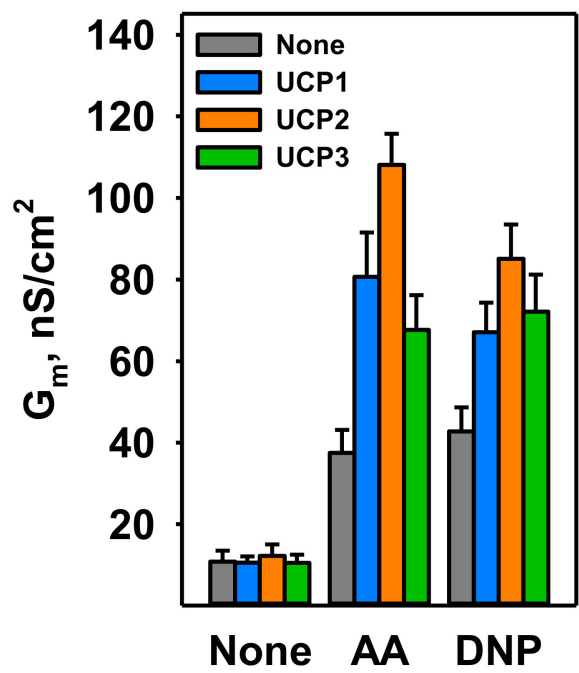

C

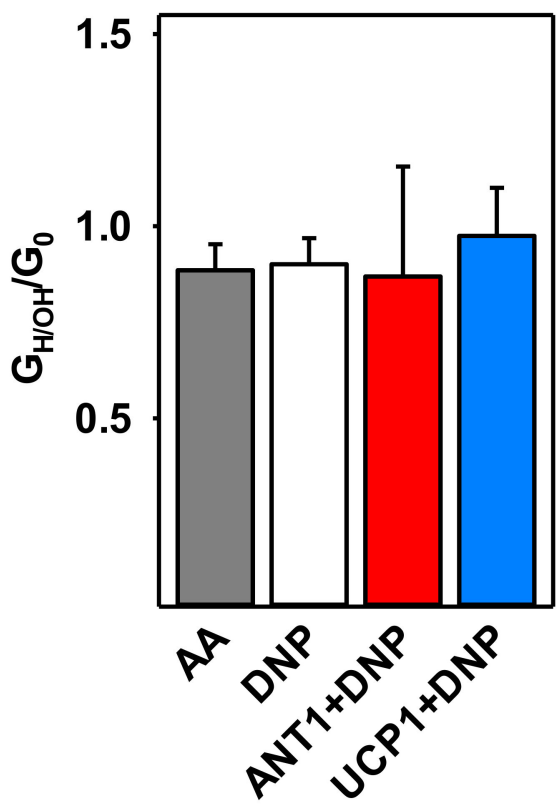

Figure 2. DNP-mediated proton transport in the presence of mitochondrial membrane proteins reconstituted in planar lipid bilayers. (A) Increase in the total specific membrane conductance $\left(G_{m}\right)$ in the presence of arachidonic acid (AA) or DNP without (gray) and with ANT1 (red). (B) Increase in $\mathrm{G}_{\mathrm{m}}$ in the presence of AA or DNP without protein (gray) or with UCP1 (blue), UCP2 (orange), or UCP3 (green). (C) The ratio of proton conductance to total membrane conductance $\left(\mathrm{G}_{\mathrm{H} / \mathrm{OH}} / \mathrm{G}_{0}\right)$ was measured at a transmembrane $\mathrm{pH}$ gradient of 0.4 . The concentrations of AA and DNP were $15 \mathrm{~mol} \%$ and $50 \mu \mathrm{M}$. For all measurements, the membranes were made of DOPC:DOPE:CL (45:45:10 mol\%). Lipid and protein concentrations were $1.5 \mathrm{mg} / \mathrm{mL}$ and $4 \mu \mathrm{g}$ per $\mathrm{mg}$ of lipid. The buffer solution consisted of $50 \mathrm{mM} \mathrm{Na}_{2} \mathrm{SO}_{4}, 10 \mathrm{mM}$ Tris, $10 \mathrm{mM} \mathrm{MES,} \mathrm{and} 0.6 \mathrm{mM}$ EGTA at $\mathrm{pH}=7.34$ and $\mathrm{T}=32{ }^{\circ} \mathrm{C}$. Data are the mean $\pm \mathrm{SD}$ of at least three independent experiments.

Figure 2A shows that the specific conductance of membranes containing DNP in the presence of ANT1 (ANT1 + DNP, red column; $\mathrm{G}_{\mathrm{m}}=80.9 \pm 9.4 \mathrm{nS} / \mathrm{cm}^{2}$ ) was approximately double that of membranes containing only DNP at a concentration of $50 \mu \mathrm{M}$ (DNP, gray 
column; $\left.\mathrm{G}_{\mathrm{m}}=42.7 \pm 5.9 \mathrm{nS} / \mathrm{cm}^{2}\right)$. Until now, only FAs have been shown to activate ANT1 directly (Figure 2A) [18,26,51,52].

To test whether uncoupling proteins can be activated by DNP in the absence of FA, we reconstituted recombinant murine UCP1, UCP2, and UCP3 (Figure S1) in bilayer membranes made of DOPC, DOPE, and CL. $\mathrm{G}_{\mathrm{m}}$ in the presence of UCPs and DNP $\left(\mathrm{G}_{\mathrm{m}}\right.$, UCP1 $\left.=67.1 \pm 7.2 \mathrm{nS} / \mathrm{cm}^{2}, \mathrm{G}_{\mathrm{m}, \mathrm{UCP} 2}=85.1 \pm 8.4 \mathrm{nS} / \mathrm{cm}^{2} ; \mathrm{G}_{\mathrm{m}, \mathrm{UCP} 3}=72.1 \pm 9.1 \mathrm{nS} / \mathrm{cm}^{2}\right)$ was again approximately double that in the presence of DNP alone $\left(\mathrm{G}_{\mathrm{m}}=42.7 \pm 5.9 \mathrm{nS} / \mathrm{cm}^{2}\right)$ (Figure 2B).

The contribution of proton conductance to the total membrane conductance $\left(\mathrm{G}_{\mathrm{H} / \mathrm{OH}} / \mathrm{G}_{0}\right)$ was determined from the shift in reverse potential in the presence of a transmembrane $\mathrm{pH}$ gradient of 0.4 [30]. Figure 2C shows that in the presence of DNP and protein (ANT1 or $\mathrm{UCP} 1$ ), the $\mathrm{G}_{\mathrm{H} / \mathrm{OH}} / \mathrm{G}_{0}$ was approximately 1 , confirming the specificity of the proton transport in all cases.

\subsection{CATR and ATP Inhibit DNP-Mediated Activation of ANT1 Only If Added before DNP}

Because CATR was able to partially restore MMP in mitochondria treated with DNP (Figure 1), we tested whether its addition would deplete the proton transport mediated by DNP in the presence of reconstituted ANT1. Interestingly, CATR decreased $\mathrm{G}_{\mathrm{m}}$ more effectively if added prior to DNP (Figure $3 \mathrm{~A}$ ). The decrease was more pronounced at the higher CATR concentration of $100 \mu \mathrm{M}(\sim 98 \%)$, indicating the specificity of the interaction.

A

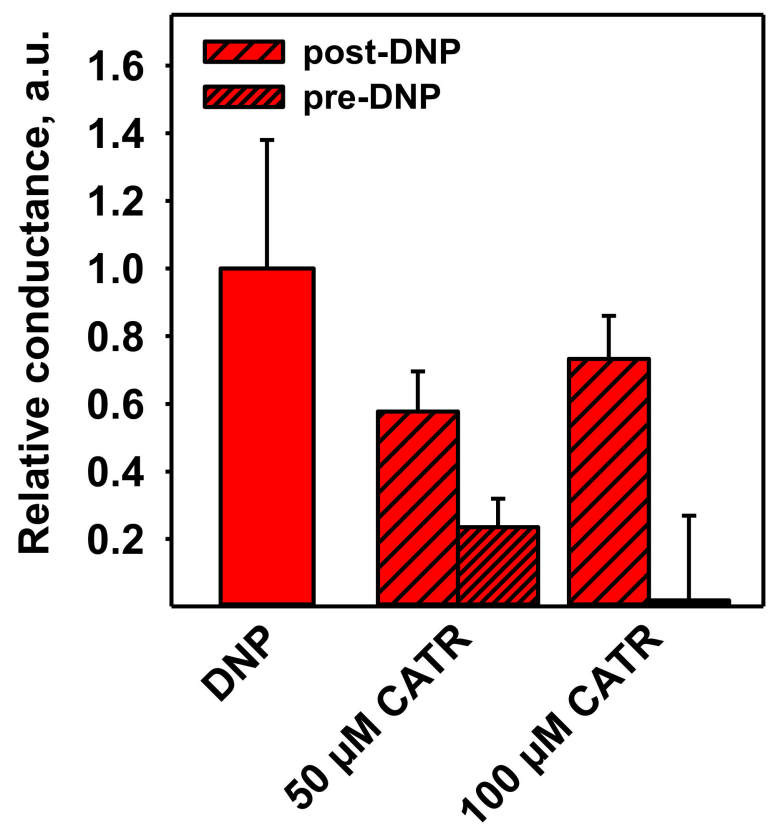

B

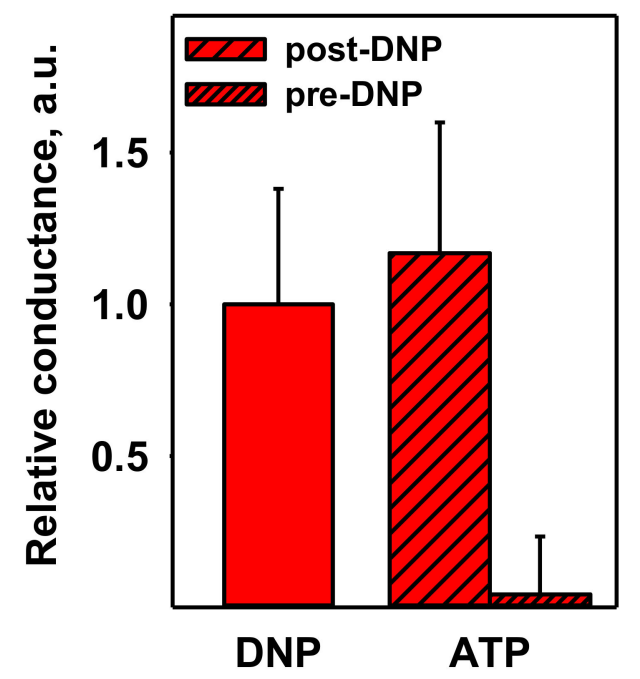

Figure 3. DNP-mediated proton transport in the presence of ANT1 can be inhibited by CATR or ATP. (A) Relative conductance of bilayer lipid membranes reconstituted with ANT1 in the presence of DNP and CATR added either after DNP (post-DNP) or before DNP (pre-DNP). (B) Relative conductance of bilayer membranes reconstituted with ANT1 in the presence of DNP and $4 \mathrm{mM}$ ATP. Relative conductance describes the ratio between the total membrane conductance, $\mathrm{G}_{\mathrm{m}}$, in the presence or absence of inhibitors to the membrane conductance measured in the presence of lipids alone (see Equation (1)). Other experimental conditions were the same as in Figure 2.

ATP was shown to be an inhibitor of FA-activated ANT1 [26], so we examined its effect on DNP-mediated proton transport as well. Figure 3B shows that $4 \mathrm{mM}$ ATP inhibited the effect of DNP by $\sim 96 \%$, further suggesting the same putative binding site for DNP, CATR, ATP, and FA. The total membrane conductance $\left(G_{m}\right)$ values of Figure 3 are shown 
in Figure S2. ATP inhibited the UCP1-UCP3-enhanced DNP-mediated uncoupling in the same manner as it did in case of ANT1 (Figure 4).

A

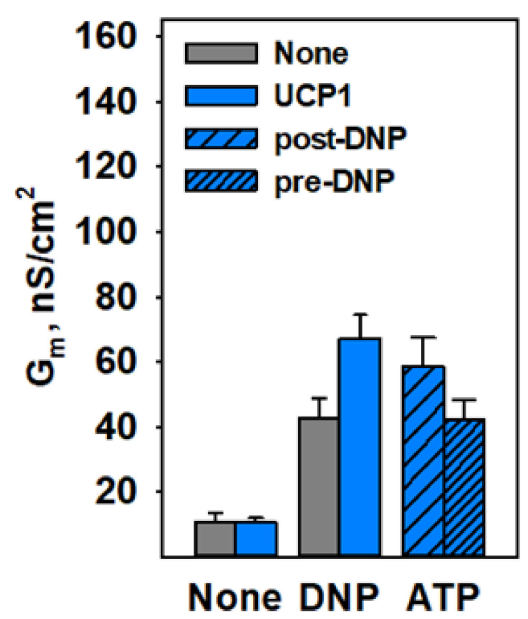

B

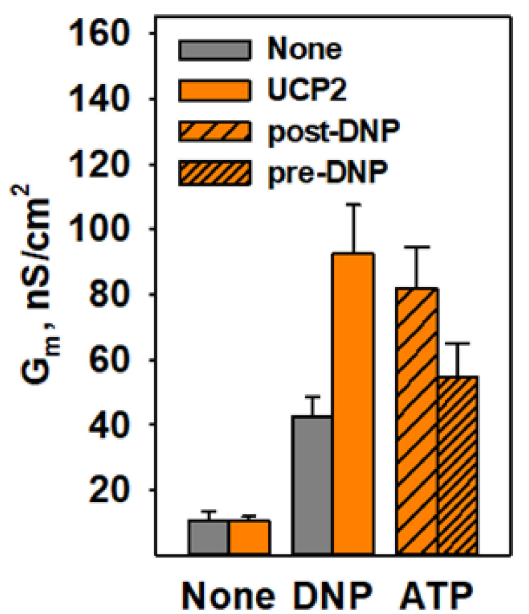

C

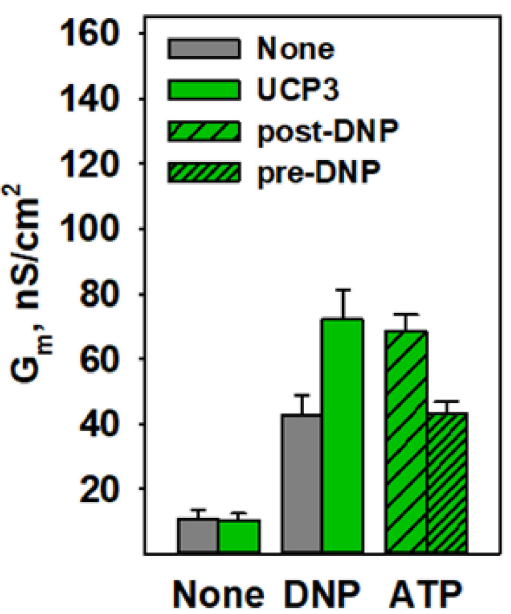

Figure 4. ATP decreased DNP-mediated proton transport enhanced by UCP1 (A), UCP2 (B), and UCP3 (C). Here, 4 mM of ATP was added either post-DNP (medium pattern) or pre-DNP (fine pattern). The experimental conditions were similar to those in Figure 2.

\subsection{R79 Is Crucial for DNP-Protein Interaction}

Because arginine 79 (R79) was previously shown to be important for the binding of CATR and ATP to ANT1 [53-55], we further evaluated the role of R79 in the interaction between DNP and ANT1. Indeed, the recombinant ANT1 in which R79 was substituted by serine using site-directed mutagenesis (ANT1 R79S) was unable to facilitate proton transport mediated by DNP (Figure 5, dark red columns). This result supported the idea that the R79 of ANT1 is crucial for the increase in proton transport in the presence of DNP.

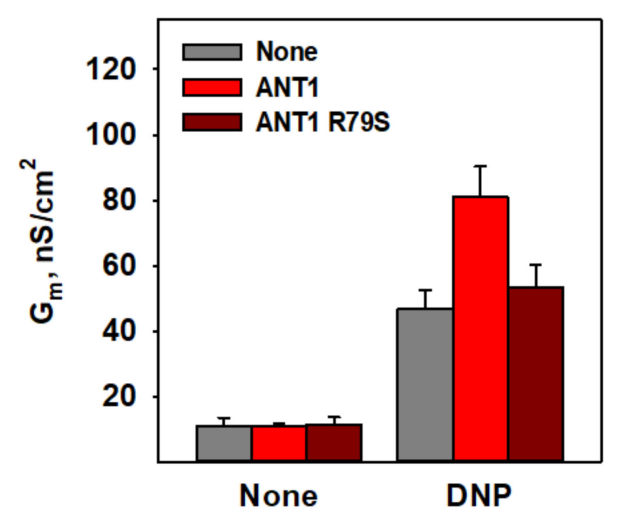

Figure 5. Effect of the ANT1 R79S mutation on DNP-mediated proton transport. Total specific membrane conductance $\left(\mathrm{G}_{\mathrm{m}}\right)$ of the lipid bilayer membranes reconstituted with ANT1 (red) or ANT1 R79S (dark red) in the presence and absence of $50 \mu \mathrm{M}$ DNP. The experimental conditions were the same as in Figure 2.

\subsection{Molecular Dynamic Simulations Show the Binding of DNP to R79 but Not to S79}

To test the putative role of R79 in the interaction of DNP with ANT1, we performed 500 ns molecular dynamic (MD) simulations for two systems: ANT1 and ANT1 R79S. Figure 6 shows that DNP bound easily to R79 in ANT1, whereas in the case of ANT1 R79S the binding was absent. Analysis of the distances between DNP and the $C_{Z}$ atom of R79 (Figure 6A) shows that the binding of DNP to R79 was not very strong and persistent, as 
evidenced by the relatively large corresponding average distance (Figure 6B). However, DNP frequently makes close contact with R79 by forming bidentate hydrogen bonds with its guanidinium side chain, which is apparently responsible for DNP binding in addition to attractive electrostatic interactions (Figure 6B, arrows; Figure 6C). In contrast, a mutation of R79 to S79 in ANT1 abolished the close contacts between DNP and the $C_{B}$ atom of serine due to the loss of attractive electrostatic interactions and favorable hydrogen bonding (Figure 6D).

A

C<smiles>CC(N)(N)NCCC[C@H](N)C(=O)O</smiles><smiles>[13CH3]C(O)[C@@H](N)C(=O)O</smiles>

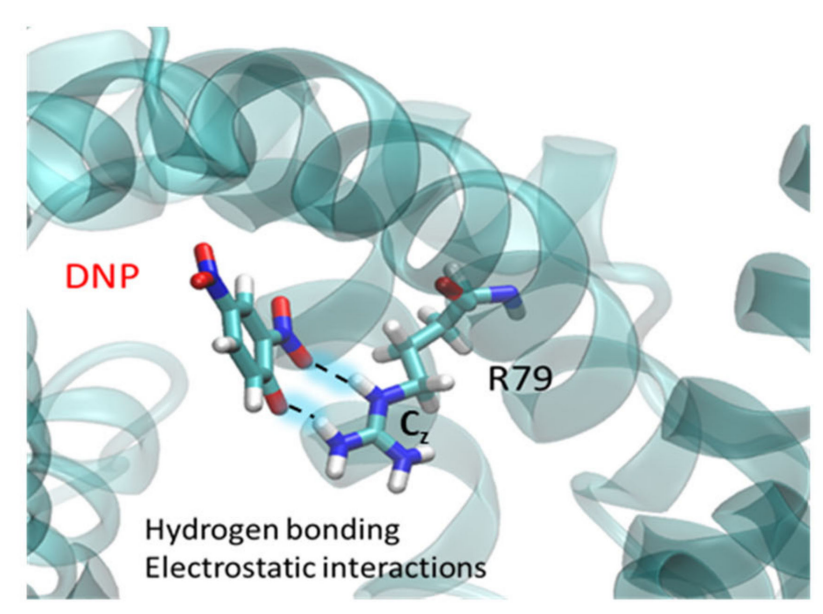

B

D
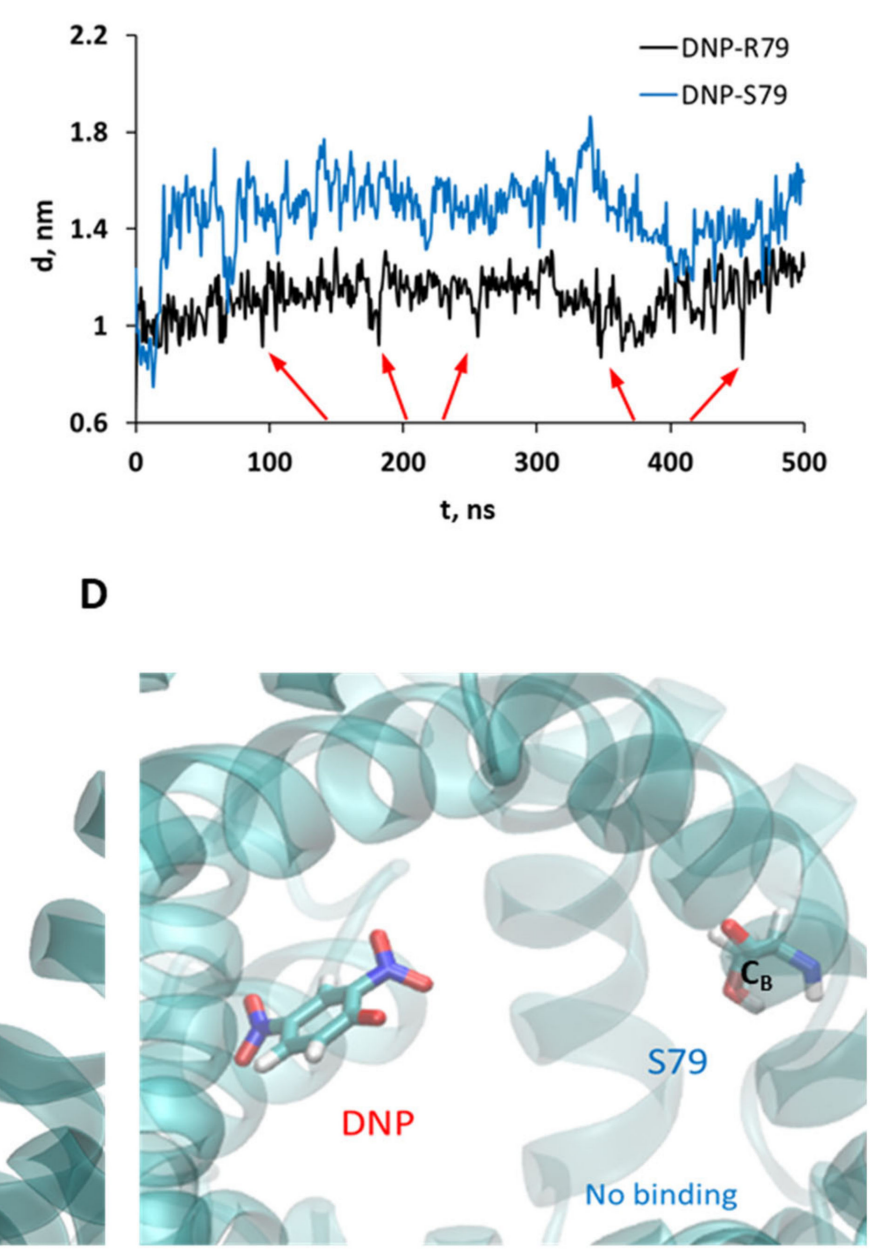

Figure 6. DNP binding in ANT1 and ANT1 R79S. (A) Structure of arginine and serine at $\mathrm{pH}=7$ in water. $\mathrm{C}_{\mathrm{Z}}$ is the central carbon atom of the guanidinium side chain in $R 79$, and $C_{B}$ is the carbon atom in the side chain of S79. (B) Analysis of the distances between DNP's center of mass and the $C_{Z}$ atom in R79 (black) and the $C_{B}$ atom in the S79 residue (blue). Red arrows indicate close contacts between DNP and R79. Selected snapshots from MD simulations of DNP in ANT1 (C) and DNP in ANT1 R79S (D).

However, the binding of DNP to R79 was not as strong as in the case of ATP [56,57]. Figure $\mathrm{S} 4$ presents an analysis of the corresponding distances between phosphorous atoms in the phosphate groups of ATP $(\mathrm{P} \alpha, \mathrm{P} \beta$, and $\mathrm{P} \gamma)$ and the $\mathrm{C}_{\mathrm{Z}}$ atom in R79 in ANT1 (Figure S4A) and the $C_{B}$ atom in S79 in the ANT1 R79S (Figure S4B), respectively. We can see that ATP bound very strongly to R79, as evidenced by the short and persistent contacts between $\mathrm{P} \alpha$ and $\mathrm{P} \beta$ atoms and R79 throughout the MD simulations. However, when R79 was mutated, the average distances from all three phosphate groups to $\mathrm{S79}$ increased, showing weaker binding to S79 due to the loss of electrostatic interactions. 


\section{Discussion}

Comparing the conductance of the pure lipid bilayer membranes and membranes reconstituted with recombinant ANT1, UCP1, UCP2, or UCP3, we revealed that proteins potentiate DNP-mediated proton transport through the membrane. Until now, only FAs were known to serve as a co-factor of the uncoupling function of these proteins. The mutation R79 in ANT1 abolished the increment in the conductance of the bilayer membrane reconstituted with protein, thus indicating DNP's putative binding site.

Our experiments on isolated mitochondria and membranes reconstituted with ANT1 or UCPs showed that DNP at a concentration of $50 \mu \mathrm{M}$ can significantly decrease the MMP (Figure 1) and increase $G_{m}$ (Figure 2). This is in agreement with a previous report about the large effects of $30 \mu \mathrm{M}$ DNP on the mitochondria [58]. Interestingly, the fact that IMM has very high protein to lipid ratio of approximately 3:1 implies that the interaction of DNP with a protein contributes significantly to the DNP's action on the mitochondria.

Both CATR and ATP were able to prevent the increase in the protonophoric action of DNP in the presence of protein, which suggested the involvement of a similar binding site. MD simulation results supported the idea that ATP binds to R79 more strongly than DNP, showing much shorter distances between ATP phosphate groups and R79, and persistent contacts between them (Figure S4). DNP also bound to R79 but, based on the distance analysis (Figure 6B), the binding of DNP was not as strong, and close contacts between DNP and R79 are not as frequent as in ATP binding.

The results of the site-directed mutagenesis showed that R79 is crucial for the DNP effect, since its replacement completely abolished the $G_{m}$ increase in the presence of protein. R79 is a component of the arginine ring made of three arginine residues, which was found to protrude into the center of the protein's cavity [55]. At the alkaline $\mathrm{pH}$ of the cytosol and mitochondrial matrix, which we imitated in our experiments, the aforementioned molecules possess at least one negative charge and interact with positively charged amino acids, with R79 either being one of them or being the critical one. As R79 plays an important role in the binding of all ANT1-specific substrates, it is possibly a highly conserved residue for the protein's functions-ATP / ADP and proton transport-regardless of which molecule acts as an uncoupler. This was also shown by the MD simulations, suggesting that the mutation of R79 to S79 weakens the interaction between DNP and the protein due to the loss of electrostatic attraction and hydrogen bonding possibilities (Figure 6C,D).

We suggest that the mechanism of the enhancement of DNP's protonophoric function by ANT1 is similar to that of fatty acids. So far, two hypotheses have been proposed to explain the induction of proton conductance by fatty acids involving ANT and uncoupling proteins (for a review, see [59]): (1) Protein accelerates the transport of the FA anion, which limits total proton transport by FA flip-flop through the lipid membrane [26,60]; (2) FA induces a conformational transition in protein, leading to proton leakage through the protein $[51,61]$. The present work argued in favor of the first mechanism of the induction of proton conductance by ANT1 [26] because FA and DNP share the R79 residue as a common binding site [62]. Further experiments investigating the exact interaction between ANT1 and DNP and outlining the mechanism are required.

Besides ANT1, UCP1-UCP3 enhance the proton transport mediated by DNP (Figure 2B). This is in agreement with the experiments on isolated rat heart mitochondria, in which we observed a more pronounced effect of DNP than in liver. Heart mitochondria not only have a higher level of ANT1 than RLM [48] but also express UCP3, which is not found in the liver $[49,63,64]$. Notably, the R79 of ANT1 is highly conserved among the SLC25 protein family, with the residues R84, R88, and R84 being homologs of it in UCP1, UCP2, and UCP3, respectively. These residues likely form a putative DNP binding site in uncoupling proteins, and their depletion would result in the complete loss of DNP-mediated proton leakage, as occurred in R79S ANT1. Furthermore, we suggest that other proton-transporting proteins, such as the aspartate/glutamate carrier, the dicarboxylate carrier, the phosphate carrier, and the 2-oxoglutarate carrier [65-68], will also potentiate the protonophoric function of DNP. 
Supplementary Materials: The following are available online at https: / www.mdpi.com/article/ 10.3390/biom11081178/s1, Figure S1: Representative silver staining of proteins used in the study, Figure S2: Representative current-voltage recordings of pure lipid bilayer membranes and membranes reconstituted with ANT1 or without ANT1 in the presence of DNP, Figure S3: Effect of ANT1 specific inhibitors on the total conductance $\left(\mathrm{G}_{\mathrm{m}}\right)$ of membranes reconstituted with ANT1 and DNP, Figure S4: ATP binding to the arginine 79 of the ANT1 or ANT1-R79S, Figure S5: DNP and ATP binding in ANT1.

Author Contributions: Conceptualization, E.E.P. and Y.N.A.; funding acquisition, E.E.P., Y.N.A., and M.V.; investigation, K.Ž., O.J., J.K., S.Š., Z.B., L.S.K., and M.V.; project administration, E.E.P.; resources, E.E.P., Y.N.A., and M.V.; supervision, E.E.P., Y.N.A., and M.V.; writing-original draft, E.E.P., K.Ž., Y.N.A., E.A.K., and M.V.; writing—review and editing, E.E.P., K.Ž., Y.N.A., O.J., J.K., E.A.K., S.Š., Z.B., L.S.K. and M.V. All authors have read and agreed to the published version of the manuscript.

Funding: This paper was supported by the European Union's Horizon 2020 MSCA-ITN-860592PROTON and the Austrian Research Fund (P31559) (to E.P.), the Russian Science Foundation (grant 21-14-00062 to Y.N.A.), and the Croatian Science Foundation (Project No. IP-2019-04-3804 to M.V.).

Institutional Review Board Statement: Not applicable.

Informed Consent Statement: Not applicable.

Data Availability Statement: The datasets generated and/or analyzed during the current study can be obtained upon reasonable request from the corresponding authors or at the following link: DOI:10.5281/zenodo.5113039.

Acknowledgments: We thank Sarah Bardakji for the excellent technical assistance. We are also grateful to Peter Pohl for helpful discussions. We thank the computer cluster Isabella based at SRCEUniversity of Zagreb, University Computing Centre, for computational resources. M.V. thanks the UOCHB Sabbatical visit program for support.

Conflicts of Interest: The authors declare no conflict of interest.

\section{References}

1. Cutting, W.; Mehrtens, H.; Tainter, M. Actions and uses of dinitrophenol: Promising metabolic applications. J. Am. Med. Assoc. 1933, 101, 193-195. [CrossRef]

2. Tainter, M.L.; Cutting, W.C.; Stockton, A. Use of Dinitrophenol in Nutritional Disorders* A Critical Survey of Clinical Results. Am. J. Public Health Nations Health 1934, 24, 1045-1053. [CrossRef]

3. Colman, E. Dinitrophenol and obesity: An early twentieth-century regulatory dilemma. Regul. Toxicol. Pharmacol. 2007, 48, 115-117. [CrossRef]

4. Koncz, D.; Tóth, B.; Roza, O.; Csupor, D. A Systematic Review of the European Rapid Alert System for Food and Feed: Tendencies in Illegal Food Supplements for Weight Loss. Front. Pharmacol. 2021, 11, 611361. [CrossRef]

5. Ebert, A.; Hannesschlaeger, C.; Goss, K.-U.; Pohl, P. Passive Permeability of Planar Lipid Bilayers to Organic Anions. Biophys. J. 2018, 115, 1931-1941. [CrossRef] [PubMed]

6. Hannesschlaeger, C.; Horner, A.; Pohl, P. Intrinsic Membrane Permeability to Small Molecules. Chem. Rev. 2019, 119, 5922-5953. [CrossRef] [PubMed]

7. Liberman, E.A.; Topaly, V.P.; Silberstein, A.Y. Charged and neutral ion carriers through bimolecular phospholipid membranes. Biochim. Biophys. Acta 1970, 196, 221-234. [CrossRef]

8. Bakker, E.; Heuvel, E.V.D.; Wiechmann, A.; Van Dam, K. A comparison between the effectiveness of uncouplers of oxidative phosphorylation in mitochondria and in different artificial membrane systems. Biochim. Biophys. Acta Bioenerg. 1973, $292,78-87$. [CrossRef]

9. Bielawski, J.; Thompson, T.E.; Lehninger, A.L. The effect of 2,4-dinitrophenol on the electrical resistance of phospholipid bilayer membranes. Biochem. Biophys. Res. Commun. 1966, 24, 948-954. [CrossRef]

10. Hopfer, U.; Lehninger, A.L.; Thompson, T.E. Protonic conductance across phospholipid bilayer membranes induced by uncoupling agents for oxidative phosphorylation. Proc. Natl. Acad. Sci. USA 1968, 59, 484-490. [CrossRef]

11. Skulachbv, V.; Sharaf, A.; Yagujzinsky, L.; Jasaitis, A.; Liberman, E.; Topali, V. The effect of uncouplers on mitochondria, respiratory enzyme complexes and artificial phospholipid membranes. Biosystems 1968, 2, 98-105. [CrossRef]

12. Liberman, E.A.; Topaly, V.P.; Tsofina, L.M.; Jasaitis, A.A.; Skulachev, V.P. Mechanism of coupling of oxidative phosphorylation and the membrane potential of mitochondria. Nature 1969, 222, 1076-1078. [CrossRef]

13. Liberman, E.; Topaly, V. Selective transport of ions through bimolecular phospholipid membranes. Biochim. Biophys. Acta Biomembr. 1968, 163, 125-136. [CrossRef] 
14. Ting, H.; Wilson, D.F.; Chance, B. Effects of uncouplers of oxidative phosphorylation on the specific conductance of bimolecular lipid membranes. Arch. Biochem. Biophys. 1970, 141, 141-146. [CrossRef]

15. Hanstein, W.G.; Hatefi, Y. Trinitrophenol: A Membrane-Impermeable Uncoupler of Oxidative Phosphorylation. Proc. Natl. Acad. Sci. USA 1974, 71, 288-292. [CrossRef]

16. Cyboron, G.W.; Dryer, R. Uncoupling of hamster brown adipose and liver mitochondria by 2-azido-4-nitrophenol and binding properties of the reagent. Arch. Biochem. Biophys. 1977, 179, 141-146. [CrossRef]

17. Kurup, C.K.R.; Sanadi, D.R. Photoaffinity labeling of uncoupler binding sites on mitochondrial membrane. J. Bioenerg. Biomembr. 1977, 9, 1-15. [CrossRef] [PubMed]

18. Andreyev, A.; Bondareva, T.; Dedukhova, V.; Mokhova, E.; Skulachev, V.; Volkov, N. Carboxyatractylate inhibits the uncoupling effect of free fatty acids. FEBS Lett. 1988, 226, 265-269. [CrossRef]

19. Lou, P.-H.; Hansen, B.S.; Olsen, P.H.; Tullin, S.; Murphy, M.P.; Brand, M.D. Mitochondrial uncouplers with an extraordinary dynamic range. Biochem. J. 2007, 407, 129-140. [CrossRef]

20. Kopustinskiene, D.M.; Jovaisiene, J.; Liobikas, J.; Toleikis, A. Diazoxide and Pinacidil Uncouple Pyruvate-Malate-Induced Mitochondrial Respiration. J. Bioenerg. Biomembr. 2002, 34, 49-53. [CrossRef]

21. Ortega, R.; Garcia, N. The flavonoid quercetin induces changes in mitochondrial permeability by inhibiting adenine nu-cleotide translocase. J. Bioenerg. Biomembr. 2009, 41, 41-47. [CrossRef]

22. Lu, Y.; Liu, S.; Wang, Y.; Wang, D.; Gao, J.; Zhu, L. Asiatic acid uncouples respiration in isolated mouse liver mitochondria and induces HepG2 cells death. Eur. J. Pharmacol. 2016, 786, 212-223. [CrossRef]

23. Antonenko, Y.N.; Denisov, S.; Khailova, L.S.; Nazarov, P.A.; Rokitskaya, T.; Tashlitsky, V.N.; Firsov, A.M.; Korshunova, G.A.; Kotova, E.A. Alkyl-substituted phenylamino derivatives of 7-nitrobenz-2-oxa-1,3-diazole as uncouplers of oxidative phosphorylation and antibacterial agents: Involvement of membrane proteins in the uncoupling action. Biochim. Biophys. Acta Biomembr. 2017, 1859, 377-387. [CrossRef] [PubMed]

24. Firsov, A.M.; Popova, L.B.; Khailova, L.S.; Nazarov, P.A.; Kotova, E.A.; Antonenko, Y.N. Protonophoric action of BAM15 on planar bilayers, liposomes, mitochondria, bacteria and neurons. Bioelectrochemistry 2021, 137, 107673. [CrossRef]

25. Skulachev, V.P. Uncoupling: New approaches to an old problem of bioenergetics. Biochim. Biophys. Acta Bioenerg. 1998, 1363, 100-124. [CrossRef]

26. Kreiter, J.; Rupprecht, A.; Škulj, S.; Brkljača, Z.; Žuna, K.; Knyazev, D.; Bardakji, S.; Vazdar, M.; Pohl, E. ANT1 Activation and Inhibition Patterns Support the Fatty Acid Cycling Mechanism for Proton Transport. Int. J. Mol. Sci. 2021, 22, 2490. [CrossRef]

27. Kreiter, J.; Beitz, E.; Pohl, E.E. A Fluorescence-Based Method to Measure ADP/ATP Exchange of Recombinant Adenine Nucleotide Translocase in Liposomes. Biomolecules 2020, 10, 685. [CrossRef] [PubMed]

28. Rupprecht, A.; Sokolenko, E.A.; Beck, V.; Ninnemann, O.; Jaburek, M.; Trimbuch, T.; Klishin, S.S.; Jezek, P.; Skulachev, V.; Pohl, E.E. Role of the Transmembrane Potential in the Membrane Proton Leak. Biophys. J. 2010, 98, 1503-1511. [CrossRef]

29. Macher, G.; Koehler, M.; Rupprecht, A.; Kreiter, J.; Hinterdorfer, P.; Pohl, E.E. Inhibition of mitochondrial UCP1 and UCP3 by purine nucleotides and phosphate. Biochim. Biophys. Acta Biomembr. 2018, 1860, 664-672. [CrossRef] [PubMed]

30. Kreiter, J.; Pohl, E.E. A Micro-agar Salt Bridge Electrode for Analyzing the Proton Turnover Rate of Recombinant Membrane Proteins. J. Vis. Exp. 2019, 143, e58552. [CrossRef] [PubMed]

31. Beck, V.; Jabůrek, M.; Breen, E.P.; Porter, R.K.; Ježek, P.; Pohl, E.E. A new automated technique for the reconstitution of hydrophobic proteins into planar bilayer membranes. Studies of human recombinant uncoupling protein 1. Biochim. Biophys. Acta Bioenerg. 2006, 1757, 474-479. [CrossRef] [PubMed]

32. Kreiter, J.; Rupprecht, A.; Zimmermann, L.; Moschinger, M.; Rokitskaya, T.; Antonenko, Y.N.; Gille, L.; Fedorova, M.; Pohl, E.E. Molecular Mechanisms Responsible for Pharmacological Effects of Genipin on Mitochondrial Proteins. Biophys. J. 2019, 117, 1845-1857. [CrossRef]

33. Johnson, D.; Lardy, H. Isolation of liver or kidney mitochondria. Anal. Biochem. 1967, 94-96. [CrossRef]

34. Åkerman, K.E.; Wikström, M.K. Safranine as a probe of the mitochondrial membrane potential. FEBS Lett. 1976, 68, 191-197. [CrossRef]

35. Škulj, S.; Brkljača, Z.; Vazdar, M. Molecular Dynamics Simulations of the Elusive Matrix-Open State of Mitochondrial ADP/ATP Carrier. Isr. J. Chem. 2020, 60, 735-743. [CrossRef]

36. Jo, S.; Lim, J.B.; Klauda, J.B.; Im, W. CHARMM-GUI Membrane Builder for mixed bilayers and its application to yeast membranes. Biophys. J. 2009, 97, 50-58. [CrossRef]

37. Wu, E.L.; Cheng, X.; Jo, S.; Rui, H.; Song, K.C.; Davila-Contreras, E.M.; Qi, Y.; Lee, J.; Monje-Galvan, V.; Venable, R.M.; et al. CHARMM-GUI Membrane Builder toward realistic biological membrane simulations. J. Comput. Chem. 2014, 35, 1997-2004. [CrossRef] [PubMed]

38. Lee, J.; Cheng, X.; Swails, J.M.; Yeom, M.S.; Eastman, P.K.; Lemkul, J.A.; Wei, S.; Buckner, J.; Jeong, J.C.; Qi, Y.; et al. CHARMM-GUI Input Generator for NAMD, GROMACS, AMBER, OpenMM, and CHARMM/OpenMM Simulations Using the CHARMM36 Additive Force Field. J. Chem. Theory Comput. 2016, 12, 405-413. [CrossRef]

39. Huang, J.; Rauscher, S.; Nawrocki, G.; Ran, T.; Feig, M.; de Groot, B.L.; Grubmuller, H.; MacKerell, A.D., Jr. CHARMM36m: An improved force field for folded and intrinsically disordered proteins. Nat. Methods 2017, 14, 71-73. [CrossRef] 
40. Vanommeslaeghe, K.; Hatcher, E.; Acharya, C.; Kundu, S.; Zhong, S.; Shim, J.; Darian, E.; Guvench, O.; Lopes, P.E.M.; Vorobyov, I.; et al. CHARMM general force field: A force field for drug-like molecules compatible with the CHARMM all-atom additive biological force fields. J. Comput. Chem. 2009, 31, 671-690. [CrossRef] [PubMed]

41. Jo, S.; Kim, T.; Im, W. Automated Builder and Database of Protein/Membrane Complexes for Molecular Dynamics Simulations. PLoS ONE 2007, 2, e880. [CrossRef] [PubMed]

42. Nosé, S. A molecular dynamics method for simulations in the canonical ensemble. Mol. Phys. 1984, 52, 255-268. [CrossRef]

43. Parrinello, M.; Rahman, A. Polymorphic transitions in single crystals: A new molecular dynamics method. J. Appl. Phys. 1981, 52, 7182-7190. [CrossRef]

44. Essmann, U.; Perera, L.; Berkowitz, M.L.; Darden, T.; Lee, H.; Pedersen, L.G. A smooth particle mesh Ewald method. J. Chem. Phys. 1995, 103, 8577-8593. [CrossRef]

45. Humphrey, W.; Dalke, A.; Schulten, K. VMD: Visual molecular dynamics. J. Mol. Graph. 1996, 14, 33-38. [CrossRef]

46. Abraham, M.J.; Murtola, T.; Schulz, R.; Páll, S.; Smith, J.; Hess, B.; Lindahl, E. GROMACS: High performance molecular simulations through multi-level parallelism from laptops to supercomputers. SoftwareX 2015, 1-2, 19-25. [CrossRef]

47. Andreyev, A.Y.; Bondareva, T.O.; Dedukhova, V.I.; Mokhova, E.N.; Skulachev, V.P.; Tsofina, L.M.; Volkov, N.I.; Vygodina, T.V. The ATP/ADP-antiporter is involved in the uncoupling effect of fatty acids on mitochondria. Eur. J. Biochem. 1989, 182, 585-592. [CrossRef] [PubMed]

48. Schonfeld, P. Does the function of adenine nucleotide translocase in fatty acid uncoupling depend on the type of mitochondria? FEBS Lett. 1990, 264, 246-248. [CrossRef]

49. Hilse, K.E.; Rupprecht, A.; Egerbacher, M.; Bardakji, S.; Zimmermann, L.; Wulczyn, A.; Pohl, E.E. The Expression of Un-coupling Protein 3 Coincides with the Fatty Acid Oxidation Type of Metabolism in Adult Murine Heart. Front. Physiol. 2018, 9, 747. [CrossRef]

50. Skárka, L.; Bardová, K.; Brauner, P.; Flachs, P.; Jarkovská, D.; Kopecký, J.; Ostádal, B. Expression of mitochondrial uncoupling protein 3 and adenine nucleotide translocase 1 genes in developing rat heart: Putative involvement in control of mitochondrial membrane potential. J. Mol. Cell. Cardiol. 2003, 35.

51. Bertholet, A.M.; Chouchani, E.T.; Kazak, L.; Angelin, A.; Fedorenko, A.; Long, J.Z.; Vidoni, S.; Garrity, R.; Cho, J.; Terada, N.; et al. H+ transport is an integral function of the mitochondrial ADP/ATP carrier. Nat. Cell Biol. 2019, 571, 515-520. [CrossRef] [PubMed]

52. Brustovetsky, N.; Klingenberg, M. The reconstituted ADP/ATP carrier can mediate H+ transport by free fatty acids, which is further stimulated by mersalyl. J. Biol. Chem. 1994, 269, 27329-27336. [CrossRef]

53. Nelson, D.; Lawson, J.E.; Klingenberg, M.; Douglas, M.G. Site-directed Mutagenesis of the Yeast Mitochondrial ADP/ATP Translocator: Six Arginines and One Lysine are Essential. J. Mol. Biol. 1993, 230, 1159-1170. [CrossRef] [PubMed]

54. Heidkämper, D.; Müller, V.; Nelson, D.; Klingenberg, M. Probing the Role of Positive Residues in the ADP/ATP Carrier from Yeast. The Effect of Six Arginine Mutations on Transport and the Four ATP versus ADP Exchange Modes. Biochemistry 1996, 35, 16144-16152. [CrossRef] [PubMed]

55. Pebay-Peyroula, E.; Dahout-Gonzalez, C.; Kahn, R.; Trézéguet, V.; Lauquin, G.J.-M.; Brandolin, G. Structure of mitochondrial ADP / ATP carrier in complex with carboxyatractyloside. Nat. Cell Biol. 2003, 426, 39-44. [CrossRef]

56. Wang, Y.; Tajkhorshid, E. Electrostatic funneling of substrate in mitochondrial inner membrane carriers. Proc. Natl. Acad. Sci. USA 2008, 105, 9598-9603. [CrossRef] [PubMed]

57. Dehez, F.; Pebay-Peyroula, E.; Chipot, C. Binding of ADP in the Mitochondrial ADP/ATP Carrier Is Driven by an Electrostatic Funnel. J. Am. Chem. Soc. 2008, 130, 12725-12733. [CrossRef]

58. Parker, V.H. Uncouplers of rat-liver mitochondrial oxidative phosphorylation. Biochem. J. 1965, 97, 658-662. [CrossRef] [PubMed]

59. Pohl, E.E.; Rupprecht, A.; Macher, G.; Hilse, K.E. Important Trends in UCP3 Investigation. Front. Physiol. 2019, 10, 470. [CrossRef]

60. Skulachev, V.P. Fatty acid circuit as a physiological mechanism of uncoupling of oxidative phosphorylation. FEBS Lett. 1991, 294, 158-162. [CrossRef]

61. Klingenberg, M. Wanderings in bioenergetics and biomembranes. Biochim. Biophys. Acta 2010, 1797, 579-594. [CrossRef]

62. Kreiter, J.; Skulj, S.; Brkljaca, Z.; Zuna, K.; Vazdar, M.; Pohl, E.E. The transport of fatty acid anions across the inner mitochondrial membrane by the adenine nucleotide translocase. Eur. Biophys. J. 2021, 50 (Suppl. 1), S57.

63. Langdown, M.L.; Smith, N.D.; Sugden, M.C.; Holness, M.J. Excessive glucocorticoid exposure during late intrauterine development modulates the expression of cardiac uncoupling proteins in adult hypertensive male offspring. Pflügers Archiv. 2001, 442, 248-255. [CrossRef]

64. Hilse, K.E.; Kalinovich, A.V.; Rupprecht, A.; Smorodchenko, A.; Zeitz, U.; Staniek, K.; Erben, R.G.; Pohl, E.E. The expression of UCP3 directly correlates to UCP1 abundance in brown adipose tissue. Biochim. Biophys. Acta Bioenerg. 2016, 1857, 72-78. [CrossRef]

65. Samartsev, V.N.; Smirnov, A.V.; Zeldi, I.P.; Markova, O.V.; Mokhova, E.N.; Skulachev, V.P. Involvement of aspartate/glutamate antiporter in fatty acid-induced uncoupling of liver mitochondria. Biochim. Biophys. Acta 1997, 1319, 251-257. [CrossRef]

66. Wieckowski, M.; Wojtczak, L. Involvement of the Dicarboxylate Carrier in the Protonophoric Action of Long-Chain Fatty Acids in Mitochondria. Biochem. Biophys. Res. Commun. 1997, 232, 414-417. [CrossRef] [PubMed] 
67. Engstová, H.; Žáčková, M.; Růžička, M.; Meinhardt, A.; Hanuš, J.; Krämer, R.; Jezek, P. Natural and Azido Fatty Acids Inhibit Phosphate Transport and Activate Fatty Acid Anion Uniport Mediated by the Mitochondrial Phosphate Carrier. J. Biol. Chem. 2001, 276, 4683-4691. [CrossRef] [PubMed]

68. Yu, X.X.; Lewin, D.A.; Zhong, A.; Brush, J.; Schow, P.W.; Sherwood, S.W.; Pan, G.; Adams, S.H. Overexpression of the human 2-oxoglutarate carrier lowers mitochondrial membrane potential in HEK-293 cells: Contrast with the unique cold-induced mito-chondrial carrier CGI-69. Biochem. J. 2001, 353, 369-375. [CrossRef] 